\title{
A INSERÇÃO DE CRITÉRIOS PRIVADOS NA POLÍTICA EDUCACIONAL DE GESTÃO DO SISTEMA DE ENSINO NO ESTADO DE MATO GROSSO DO SUL (2007-2013)
}

INSERT CRITERIA IN PRIVATE EDUCATIONAL POLICY OF

EDUCATION SYSTEM MANAGEMENT IN THE STATE OF SOUTH

MATO GROSSO DO SUL (2007-2013)

Andressa Gomes de Rezende Alves ${ }^{1}$

\begin{abstract}
RESUMO: O trabalho analisa como se configurou a inserção de critérios privados no âmbito das políticas educacionais de gestão do sistema de ensino materializadas pela Secretaria de Estado de Educação de Mato Grosso do Sul (SED/MS) no período de 2007 a 2013. Trabalhouse com pesquisa bibliográfica e documental. Constatou-se a substituição da gestão democrática por outra lógica de gestão pautada por objetivos em escala organizacional com vistas à Qualidade Total da educação. Assim, a SED/MS buscou se adequar ao modelo gerencial, que tem como base o princípio da eficiência, com ênfase nos resultados, mediante a operacionalização da proposta "Educação para o Sucesso". Tal política alterou, por exemplo, os processos para o provimento de cargo de diretor da escola, à medida que instituiu sistemas avaliativos por meio de certificação ocupacional como instrumento de meritocracia e competição para a função de diretor das escolas estaduais.
\end{abstract}

Palavras-chave: Política Educacional. Gestão da Educação Básica. Gestão do sistema de ensino de Mato Grosso do Sul

\begin{abstract}
The paper analyzes how to set up the inclusion of private criteria in the context of educational policy educational system management materialized by the Ministry of Education of Mato Grosso do Sul (SED/MS) from 2007 to 2013. He worked with bibliographical and documentary research. It was found to replace the democratic management by another logical management guided by goals in organizational scale aimed at Total Quality Education. Thus, SED / MS sought suit management model, which is based on the principle of efficiency, with an emphasis on results through the implementation of the proposed "Education for Success". This proposal has changed, for example, procedures for the provision of post of school principal as establishing assessment systems through occupational certification as an instrument of meritocracy and competition for the director function of state schools.
\end{abstract}

Keywords: Educational Policy. Basic Education Management. Mato Grosso do Sul of the education system management

\section{Introdução}

O objetivo deste trabalho constituiu-se em analisar como se configurou a inserção de critérios privados no âmbito das políticas educacionais de gestão do sistema de ensino

\footnotetext{
1 Doutoranda em educação pela Universidade Federal de Mato Grosso do Sul (UFGD). E-mail: andressa_rezend@hotmail.com
} 
materializadas pela Secretaria de Estado de Educação de Mato Grosso do Sul (SED/MS) no período de 2007 a 2013.

Pontua-se que a administração governamental que se iniciou em 2007, implantou na política educacional de gestão do sistema e das escolas da Rede Estadual de Ensino uma proposta que já havia sido experimentada na Rede Municipal de Educação no município de Campo Grande, capital do estado de Mato Grosso do Sul, entre os anos de 2001 a 2004, período no qual André Puccinelli exercia seu segundo mandato de prefeito.

Observa-se que a proposta "Educação para o Sucesso" é uma opção de política educacional de gestão de sistema e de unidades escolares em uma unidade subnacional que se insere no contexto da reforma administrativa do Estado brasileiro dos anos de 1990, e que colocou para a administração estatal os princípios da gestão gerencial.

Nesse contexto, a gestão gerencial

\begin{abstract}
Introduz elementos das teorias e técnicas da gerência empresarial e do culto da excelência nas escolas públicas. Isso enfatizando a questão da qualidade e a necessidade de atender localmente as demandas do cidadão-cliente. Assim, procura-se estabelecer um replanejamento institucional, inspirado tanto no neoliberalismo como nas práticas peculiares à gestão empresarial, segundo os pressupostos da qualidade total: privilegiamento da administração por projetos com objetivos previamente estabelecidos, baseados localmente e com traços competitivos. Nesse contexto, o gerencialismo, que é uma das marcas das reformas educativas em escala planetária, implica uma nova postura dos gestores que se tornam responsáveis pelo delineamento, pela normatização e pela instrumentalização da conduta da comunidade escolar na busca dos objetivos traçados. (AZEVEDO, 2002, p. 59).
\end{abstract}

O modelo de gestão em tela para a Rede de Ensino municipal se sustentou na parceria firmada entre a Prefeitura de Campo Grande e o Instituto Ayrton Senna (IAS), que implantou o Programa Escola Campeã (PEC), e tomou como imperativo as diretrizes da administração educacional proposta pela Fundação Luís Eduardo Magalhães (FLEM), sediada no estado da Bahia (RODRIGUEZ et al., 2010).

Há que se pontuar que, entre as Redes de Ensino do estado de MS e do município de Campo Grande no âmbito da gestão de sistemas e de escolas, construíram histórias diferentes a partir de 1991.

De fato, na Rede Estadual de Ensino, em 1991, instituiu-se o Programa "Uma proposta de Educação para MS - educação pública e democrática" cujo eixo central foi a eleição de diretor e do colegiado escolar. As administrações governamentais subsequentes, contudo, promoveram rupturas, continuidades e descontinuidades na política educacional de gestão da Rede Estadual de Ensino. 
No município de Campo Grande, desde sempre, a forma de provimento do cargo de diretor de escola tem sido por meio de indicação do Chefe do Executivo. Em que pese alterações ocorridas neste processo a partir da parceria firmada entre a Prefeitura Municipal e o IAS instituiu processos de formação e avaliação para o provimento do cargo de diretor de escola, por meio da certificação ocupacional como instrumentos de meritocracia e competição.

Diante disso, o pressuposto deste trabalho é que o processo de certificação ocupacional para diretores de escolas, implantado no município de Campo Grande, migrou para a Rede Estadual de Ensino a partir de 2007 na gestão governamental de André Puccinelli e que foi se materializando por meio do Programa "Educação para o Sucesso".

Assim, na Rede Estadual de Ensino, os diretores de escolas continuam sendo eleitos pela comunidade escolar e de seu entorno, contudo, tiveram que se submeter ao mesmo processo de certificação ocupacional que os diretores da Rede Municipal de Ensino. Trabalhouse com dados disponibilizados pela mídia estadual em meio eletrônico, dados da Secretaria de Estado de Educação e a literatura pertinente à temática.

Esse cenário permitiu observar que a gestão democrática de sistemas de ensino e de escolas vem sendo, paulatinamente, substituída pela gestão gerencial da educação por meio de legislações específicas e de programas de gestão que estão regulando novas relações na organização do trabalho na escola, tendo como centro do processo a gestão.

\section{A política de gestão para o sistema estadual de ensino no estado de Mato Grosso do Sul: a perspectiva da "Educação para o Sucesso"}

A partir de 2007, a Rede Estadual de Ensino do estado de Mato Grosso do Sul passou a conviver com a proposta de "Educação para o Sucesso". O que ocorreu de fato na política educacional de Mato Grosso do Sul, é que o governo de André Puccinelli trouxe para a política educacional de gestão do sistema de ensino a cultura gerencial da Pedagogia do Sucesso (OLIVEIRA, 2004) que foi implantada na Rede Municipal de Campo Grande, quando se estabeleceu a parceria com o IAS.

Robertson e Verger (2012) constatam que o Estado modifica sua cultura organizacional mediante a aprendizagem com o setor privado no nível gerencial. Ainda observam que o setor público aproveita a parceria com a finalidade de apreender a cultura organizacional trabalhada pelo setor privado e empregam características como flexibilidade, abertura às demandas sociais, incentivos à eficiência, planejamento estratégico do sistema de ensino, entre outras. 
A "Educação para o Sucesso" alterou significativamente o processo de eleição para diretores e também instituiu uma política de premiação aos melhores alunos. Inicialmente, o governador André Puccinelli considerou importante rever o processo de eleição para diretor que se daria em 2008 e cogitou até a eliminação do pleito eleitoral. No entanto, com a reação dos trabalhadores em educação organizados na Federação dos Trabalhadores em Educação de Mato Grosso do Sul (FETEMS), foi necessário rever posições.

Embora a política educacional do estado não recorreu à parcerias com setores privados, como ocorreu no município de Campo Grande, ressalta-se que, na administração de 2007 a 2013, ganhou status os modelos de administração embasados nos postulados gerencialistas, pois o que observou-se foi que "[...] as instituições públicas e os governos formulam e implementam políticas em função de lógicas de actuação de tipo empresarial" (CARDOSO, 2009, p. 821).

Assim, abrem-se novas possibilidades de relação público/privada com outro formato, quando o estado de mato Grosso do Sul não firma uma parceria com o setor privado, mas insere em sua política pública a concepção privada de "Educação para o Sucesso. As distintas parcerias público/privadas vão desde a construção, a gestão e a manutenção de infraestrutura, a defesa de políticas, prestação de serviços, estão fundamentadas nos princípios liberais.

Cardoso (2009) distingue os novos contornos que vêm sendo estabelecido na relação público/privada, primeira, a distinção entre a transferência de responsabilidade do Estado para entidades privadas e, a segunda, quando as ações e processos de caráter privado são integrados nas instituições estatais, mudando a lógica de gestão do público, que toma como parâmetro o privado.

Segundo a autora, fazer essa distinção é fundamental porque "[...] a presença de formas de gestão e de financiamento empresariais ou de mecanismos de mercado nas instituições públicas ocorre mesmo sem que exista transferência dessas responsabilidades estatais para entidades privadas”. (CARDOSO, 2009, p. 821).

A proposta de educação que foi implantada na Rede Estadual de Ensino esteve em consonância com os pressupostos de sociabilidade capitalista, que objetivava a conformação de um "novo homem" para uma sociedade em transformação, o que consolida, com isso, as propostas de cunho neoliberal para a educação.

Como esclarece Falleiros (2005, p. 211), coube à escola ser o

[...] espaço privilegiado para a conformação técnica e ético-política do 'novo homem', de acordo com os princípios hegemônicos. O 'novo homem' nessa visão de mundo deve: sentir-se responsável individualmente pela 
amenização de uma parte da miséria do planeta e pela preservação do meio ambiente; estar preparado para doar uma parcela do seu tempo livre para atividades voluntárias nessa direção; exigir do Estado em senso estrito transparência e comprometimento com as questões sociais, mas não deve jamais questionar a essência do capitalismo. (FALLEIROS, 2005, p. 211, grifo nosso).

Sob essa ótica, a educação como prática social e, mais especificamente, a educação escolar foi elevada à condição de lócus da construção de uma "nova pedagogia da hegemonia", ou seja, uma pedagogia da conformação e da conciliação que foi imposta pelo pensamento hegemônico (NEVES, 2005).

Historicamente, no estado de Mato Grosso do Sul, a gestão democrática foi instituída pelo Decreto $n^{\circ}$ 5.868/1991 (MATO GROSSO DO SUL, 1991), que dispôs sobre a estrutura básica das unidades escolares da Rede Estadual, regulamentou a eleição de diretor e o colegiado escolar, além de que os especialistas em educação tornaram-se coordenadores pedagógicos na Rede Estadual de Ensino.

Percebe-se no estado de MS uma tendência em assumir políticas de padrões nacionais e de orientações internacionais, pois a política educacional objetivou profissionalizar a gestão por meio de ferramentas de controle, focando na aplicação de técnicas e princípios gerenciais que nortearam a administração empresarial, com o intento de promover uma gestão mais eficaz.

Observou-se na política educacional sul-mato-grossense que a educação é elevada à posição estratégica para alcançar um pleno desenvolvimento econômico. As ações tendem a modificar o caráter do ensino público, a partir da introdução de incentivos e prêmios oferecidos com o objetivo de aumentar os resultados das avaliações, ressaltando que estas têm sido apresentadas e justificadas como propulsora de qualidade.

Para a gestão do sistema de ensino e de escola a propalada gestão democrática da educação instituída pela Constituição Federal de 1988 passou a conviver com a chamada gestão gerencial. O modelo gerencial retirou do Estado à função de provedor para assumir a função de regulador da iniciativa privada, ou seja, ocorreu uma mudança na orientação de sua ação em termos de investimento nas políticas sociais.

Trata-se de um esforço para a educação do conjunto da população referente aos valores do mercado, visando criar uma ampla base humana adequada às exigências do desenvolvimento capitalista em nosso país. A tarefa que se coloca para os empresários é não só o consenso da força de trabalho presente, como também a do futuro (ANDRADE, 2008).

Esse cenário expressou-se na conjuntura de MS, pois, com a posse do novo governo em 2007, anulou-se qualquer possibilidade de aproveitamento das propostas educacionais de 
gestões anteriores, tendo em vista que a proposta de gestão peemedebista de educação, anunciada como "Educação para o Sucesso", foi referenciada nos valores de mercado.

Essa proposta de educação guarda estritas relações com a perspectiva da pedagogia da qualidade total (RAMOS, 1992), que tem como objetivo principal eliminar resultados negativos de repetência e evasão escolar e com isso promover o sucesso escolar. E ainda, o reforço na constituição de políticas individualizadas, em que o foco é desenvolver habilidades e capacidades dos sujeitos, além do culto à meritocracia que defende que o sucesso e o fracasso é resultado da ação e desempenho individual.

A proposta de "Educação para o Sucesso" consistiu em um conjunto de programas desenvolvidos pela SED/MS que teve como finalidade a busca da qualidade e excelência da educação, "trata-se de implementar novas políticas para a educação, que envolvam uma profunda mudança cultural das Secretarias de Educação e das escolas" (OLIVEIRA, 2004, p. $65)$.

Sob esse intento, todas as ações e investimentos feitos na educação sul-mato-grossense são amplamente projetados e divulgados pela mídia local, são constantes as campanhas midiáticas veiculadas pelo governo do estado na promoção e divulgação da política de "Educação para o Sucesso".

O marketing da "Educação para o Sucesso" é feito por meio da mídia televisiva, de propagandas e programas, via internet, site da SED/MS, jornais impressos, sites de notícias, Revista “Acontece: desafios e conquistas do ensino estadual” que é uma publicação da SED.

A "Educação para o Sucesso" está permeada de um processo até então incógnito no estado, sustentada por um forte apelo midiático e encoberta pela ideologia da "nova cidadania". Esse processo vem transformando o espaço público em espaço privado, transpondo a solidariedade sistêmica para a solidariedade individual e coloca o cidadão a serviço da caridade humana o que significa um retrocesso aos direitos socialmente conquistados.

Foi nesse cenário, que o poder executivo do estado de MS apresentou o programa Escola para o Sucesso, considerado o programa prioritário do governo. Tal programa tem como meta investir na educação dos alunos sul-mato-grossenses, além de prepará-los para serem bons profissionais e bons cidadãos no futuro. Corrobora pressupostos da teoria da qualidade total da educação, qual seja, a busca de resultados de eficácia e de eficiência do processo educacional, tomando como imperativo os padrões de mercado.

Observa-se que a finalidade da implantação do programa é de "subsidiar as decisões sobre a implementação das políticas educacionais voltadas para a elevação da qualidade, 
equidade e eficiência do ensino e da aprendizagem [...]" (MATO GROSSO DO SUL, 2010a, p. 26).

Tal prerrogativa orienta-se pelos princípios que norteiam a gestão gerencial que defende os pressupostos de mais eficiência e eficácia na educação. Com isso, a gestão democrática da educação foi substituída pela administração gerencial, que atém aos mecanismos de controle de processos e de resultados, buscando os melhores índices de eficiência e de resultados.

O programa de premiação foi instituído pelo poder executivo do Estado de Mato Grosso do Sul mediante a Lei $\mathrm{n}^{\circ}$ 3.966, de 23 de setembro de 2010 (MATO GROSSO DO SUL, 2010b) e considerou como objetivo "valorizar escolas, professores e alunos que apresentem os melhores desempenhos com base nos indicadores educacionais estabelecidos pela Secretaria de Estado de Educação" (MATO GROSSO DO SUL, 2010b).

O "Escola para o Sucesso" foi regulamentado em 2011, pelo Decreto no 13.117, de 3 de fevereiro de 2011(MATO GROSSO DO SUL, 2011) e publicado no Diário Oficial do Estado, de 4 de fevereiro de 2011. De acordo com esse Decreto, os estudantes das escolas estaduais de Mato Grosso do Sul que apresentarem melhor desempenho escolar, com base nas avaliações bimestrais e assiduidade às aulas, receberão, anualmente, prêmios em espécie, equipamentos ou materiais, de acordo com as definições do governador do Estado.

Os prêmios são meios de estimular os alunos da Rede Estadual de Ensino para que tenham uma qualidade igual ou superior aos alunos das escolas particulares e, mais ainda, a premiação é um incentivo para que as crianças estudem e tenham um bom desempenho para serem bons profissionais. A ideia de premiação perpassa pela lógica do mercado o que estimula nos alunos e nas instituições escolares a competitividade, visto que esses devem alcançar bons resultados para a garantia de padrão de qualidade, o que favorece colocar os alunos e as escolas no patamar dos vencedores.

Segundo Robertson (2013), uma das consequências da competição por meio de prêmios é a criação da concorrência acirrada em vários níveis e a consequente necessidade de regular essa concorrência. Desse modo, a concorrência necessariamente produz perdedores assim como ganhadores: "trata-se, portanto, de uma medida de resultado final, interpretada em uma perspectiva individualizada, desconsiderando as condições do sistema de ensino que, sem dúvida, induzem a produção de 'competências' e 'incompetências' nos alunos" (SOUZA; OLIVEIRA, 2003, p. 884).

A avaliação nesse caso torna-se um mecanismo indutor da excelência e, nesse sentido, o sistema de ensino de MS não intenta buscar subsídios para intervir precisamente nas instituições escolares, mediante políticas para a educação. Não se tem elementos, por meio 
dessa medida tomada pela SED/MS, de melhorias das unidades escolares e do sistema de ensino.

Já a entrega de kits escolares e uniformes para todos os alunos da rede estadual de MS, representa para a SED uma forma de estimular o estudo. São repassados aos estudantes de acordo com o ano escolar que estão cursando e são diferenciados conforme o mesmo critério. Isso significa que se o aluno não conseguir êxito na escola, a responsabilidade é repassada à família e ao aluno, pois, considera-se que o governo propicia condições para que esse aluno frequente a escola e isso significa que a "culpa" pelo fracasso ou sucesso é do "[...] aluno que, porque não se dedica o suficiente às atividades e deveres, e da família, porque não o estimula ou o acompanha na frequência e ritmo necessários" (ARELARO, 2007, p. 916).

Nessa perspectiva, a educação é vista a partir da lógica meritocrática e não possui como referencial uma educação que vise ao atendimento a todos os cidadãos e sim exclui parcelas de alunos, em prol de promover o sucesso de poucos, o que faz da educação um rol de competição em busca da premiação ao final de cada ano letivo, que responsabiliza a comunidade escolar pelo sucesso ou fracasso do processo educacional.

Para Adrião (2006, p. 80):

Atribuir aos testes o status indicador de desempenho escolar é induzir o trabalho pedagógico a partir de uma limitada percepção do que seja educação. O máximo que se consegue com esse tipo de instrumento é "fotografar" uma parcela do produto da escola, o que não informa sobre a melhoria da qualidade.

De fato, a educação não pode ser vista de forma focalizada, ou melhor, na busca pela aprovação ou por resultados desejáveis. A medida que não se consegue abstrair do processo educacional a finalidade de preparar os cidadãos não somente para o trabalho, mas acima de tudo para gozar plenamente de todos os seus direitos, podendo assim, influir no status quo, com vistas à sua formação integral.

Diante desse cenário imposto na política educacional de MS, em que estabeleceu nos processos educacionais a lógica de mercado, expressa mediante procedimentos e valores decorrentes do capitalismo, a gestão dos sistemas e das unidades escolares é vista, de modo particular nas premiações feitas aos melhores alunos, considerada a meritocracia.

Longe de alcançarem a propalada qualidade por meio de políticas como a "Educação para o Sucesso", essa proposta adota uma filosofia pautada na qualidade total e na busca por excelência e sucesso dos alunos, por meio da distribuição de kits escolares e prêmios. Nesse sentido, a política educacional da rede estadual de educação sul-mato-grossense está fortemente imbuída por princípios que regem o modo de produção capitalista, de busca de resultados e 
competição entre os estudantes, sem que haja uma política que assegure uma educação de qualidade pautada por princípios democráticos, como garantido na Constituição Federal de 1988, princípios caros para a efetivação da educação como um direito social.

A classe idealizadora dessas propostas para a educação elabora teorias que permitem legitimar suas posições de privilégio. Para tanto, a meta de enriquecer o indivíduo como ser humano e cidadão supostamente criaria uma sociedade mais harmoniosa e elevaria a sociedade a um nível de desenvolvimento maior, tornando-a mais competitiva.

Com a finalidade de atingir essas metas, a proposta de "Educação para o Sucesso", embasada nos pressupostos da qualidade total, utiliza meios como a flexibilização dos processos, o uso e controle de dados estatísticos a fim de verificar os avanços alcançados, as avaliações periódicas, o incentivo e motivação da comunidade escolar mediante premiações e a construção e reformas de prédios, a capacitação dos agentes, no caso dos gestores, com as provas de certificação. Enfim, são estratégias respaldadas pelo paradigma da qualidade total, que legitimam teoricamente na instituição escolar o neoliberalismo.

\section{A materialização na gestão escolar: o papel dos diretores de escolas na rede estadual de ensino do estado de Mato Grosso do Sul}

Na política educacional de gestão do sistema de ensino de MS, no entretempo 2007 a 2013, coube ao diretor gerenciar eficazmente a escola com a perspectiva de que com uma educação de qualidade, os alunos irão aprender e terão sucesso. Por conta dessa visão em que o gerenciamento eficaz da escola é o seu ponto alto, essa política investe no preparo dos diretores.

Essa proposta de gestão de sistema e de unidades escolares dispôs sobre a certificação ocupacional de diretores de escolas concomitante à eleição. Assim estão a conviver nas escolas estaduais os dois processos: ao tempo que o diretor de escola é eleito, só é nomeado pelo poder executivo estadual se submeter ao processo de certificação ocupacional e ainda compor a lista tríplice de livre escolha.

Tem-se assim o quadro propício para, no cenário da reforma do Estado brasileiro em busca de sua modernização, as unidades subnacionais aderirem ou mesmo serem protagonistas de políticas com vistas a reconfigurações importantes no que tange a administração pública.

Portanto, entende-se que a gestão seja a estratégia mais genuína para a garantia das mudanças anunciadas. Dentro dessa perspectiva, constata-se a centralidade do papel do diretor escolar na proposta de "Educação para o Sucesso". Pois, o diretor é considerado o líder, assim como o principal responsável pela gestão do aprendizado. 
Ao diretor é atribuída a responsabilidade de atrair, manter e desenvolver a instituição, além de ter de organizar seu tempo de forma eficiente para que a escola seja eficaz e garantir um sistema com foco na aprendizagem e sucesso do aluno (SHIROMA; GARCIA; CAMPOS, 2011).

Assim, em 2007, com André Puccinelli na chefia do poder executivo estadual, implantou-se, por meio da Secretaria Estadual de Educação, outra concepção de gestão de educação em nível de sistema e de unidade escolares, a certificação ocupacional.

\section{Considerações finais}

A gestão estadual que se iniciou em 2007 vem conduzindo a política educacional de gestão do sistema, a partir dos pressupostos, princípios e diretrizes da Pedagogia do Sucesso (OLIVEIRA, 2004). A proposta de "Educação para o Sucesso" que ordenou a gestão do sistema de ensino e das unidades escolares tem sua matriz teórico-ideológica na Pedagogia da Qualidade Total (RAMOS, 1992).

Observou-se o reforço na constituição de políticas individualizadas, em que o foco é desenvolver habilidades e capacidades dos sujeitos. Além disso, o culto à meritocracia defende que o sucesso e o fracasso é resultado da ação e desempenho individual, tais aspectos que caracterizam a Pedagogia do Sucesso.

Nas ações e deliberações decorridas da proposta de "Educação para o Sucesso", ficou clara a estratégia de inserir critérios privados na gestão da Secretaria de estado de Educação, a partir da instauração de influências, políticas e determinações emanadas da lógica gerencial.

Constatou-se que o poder público não se retira de seu papel de produtor do direito à educação. Entretanto, o que ocorreu é que o estado incorporou na execução de sua política educacional orientações privadas, ou seja, manteve a estrutura pública, mas introduz a lógica privada em suas ações.

Esse processo na prática escolar culminou, entre outras ações, com a instituição do processo de certificação ocupacional para diretores de escola. Essa alteração se deu por meio da promulgação da Lei $\mathrm{n}^{\mathrm{o}} 3.479$ de 20 de dezembro de 2007, que alterou o processo eletivo de dirigentes escolares da Rede Estadual de Ensino e institui o processo seletivo para a escolha dos diretores.

A proposta de "Educação para o Sucesso" enfatizou a formação e a avaliação periódica do desempenho dos diretores das escolas, promoveu cursos de capacitação e alterou os moldes de escolha de diretor de escola construído historicamente pela política educacional do estado. 
É nesse cenário que se inseriu a proposta de problematizar aspectos concernentes à ação da relação púbico/privado, que se dá tanto com a privatização na e da educação (ROBERTSON; VERGER, 2012). Isto é, o que ocorreu na gestão do sistema de ensino do estado de MS foi a inserção da cultura organizacional trabalhada pelo setor privado que empregam características como flexibilidade, abertura às demandas sociais, incentivos à eficiência, planejamento estratégico do sistema de ensino, entre outras.

\section{REFERÊNCIAS}

ADRIÃO, T. Educação e produtividade: a reforma do ensino público e a desobrigação do Estado. São Paulo: Xamã, 2006.

ANDRADE, F. A. de. A formação do "cidadão-trabalhador": educação e cidadania no contexto do "novo industrialismo". In: NEVES, L. M. W. (Org.). Educação e Políticas no limiar do século XXI. Campinas: Autores Associados, 2008. p. 59-78.

ARELARO, L. R. G. Formulação e implementação das políticas públicas em educação e as parcerias público-privadas: impasse democrático ou mistificação política? Educação $e$ Sociedade, Campinas, SP, v. 28, n. 100, out. 2007. Disponível em: < http://www.scielo.br/pdf/es/v28n100/a1328100.pdf>. Acesso em: 09 jul. 2012.

AZEVEDO, J. M. L. de. Implicações da nova lógica de ação do Estado para a educação municipal. Educação \& Sociedade, Campinas, v. 23, n. 80, p. 49-71, set. 2002.

CARDOSO, C. M. Governar o Estado para a participação de entidades privadas na provisão, financiamento e gestão dos sistemas educativos na União Europeia. Educação \& Sociedade, Campinas, v. 30, n. 108, p. 819-843, out. 2009.

FALLEIROS, I. Parâmetros curriculares nacionais para a educação básica e a construção de uma nova cidadania. In: NEVES, L. M. W. (Org.). A nova pedagogia da hegemonia: estratégias do capital para educar o consenso. São Paulo: Xamã, 2005. p. 209-235.

MATO GROSSO DO SUL. Decreto n. 5.868, de 17 de abril de 1991. Dispõe sobre a estrutura básica das unidades escolares da rede estadual de ensino e dá outras providências. Campo Grande, 1991. Disponível em:

<http://aacpdappls.net.ms.gov.br/appls/legislacao/secoge/govato.nsf/fd8600de8a55c7fc04256 b210079ce25/a37ca80a54364aec04256e2d006897b2?OpenDocument>. Acesso em: 14 maio 2013.

MATO GROSSO DO SUL. Diário Oficial [do] Estado de Mato Grosso do Sul, Campo Grande, MS: Governadoria, 2010a. MENSAGEM/GABGOV/MS/No 34/2010. Campo Grande, 06 jul. 2010.

MATO GROSSO DO SUL. Lei no 3.966, de 23 de setembro de 2010. Institui o Programa Escola para o Sucesso na Rede Estadual de Ensino, e dá outras providências. Diário do Oficial [do] Estado de Mato Grosso do Sul, Campo Grande, MS, n. 7.795, de 24 de set. de 2010b, p. 23.

MATO GROSSO DO SUL. Decreto ${ }^{\circ}$ 13.117, de 3 de fevereiro de 2011. Regulamenta disposições da Lei n. 3.966, de 23 de setembro de 2010, que institui o Programa Escola para o Sucesso na Rede Estadual de Ensino. Diário do Oficial [do] Estado de Mato Grosso do Sul, Campo Grande, MS, n. 7.882, de 4 de fev. de 2011, p. 63. 
NEVES, L. M. W. A sociedade civil como espaço estratégico de difusão da nova pedagogia da hegemonia. In: (Org.). A nova pedagogia da hegemonia: estratégias do capital para educar o consenso. São Paulo: Xamã, 2005. p. 85-125.

OLIVEIRA, J. B. A. A pedagogia do sucesso: uma estratégia política para corrigir o fluxo escolar e vencer a cultura da repetência. São Paulo: Saraiva, 2004.

PERONI, V. M. V. Parcerias entre prefeituras e esfera privada: estratégias privatizantes para a oferta da educação pública em São Paulo? In: ADRIÃO, T. (Org.); PERONI, V. (Org.).

Público e privado: novos elementos para o debate. 1. ed. São Paulo: Xamã, 2008. p. 111-127.

RAMOS, C. Excelência na educação: a escola de qualidade total. Rio de Janeiro: Qualitymark, 1992.

ROBERTSON, S.; VERGER, A. A origem das parcerias público-privada na governança global da educação. Educação e Sociedade, Campinas, v. 33, n. 121, p. 1133-1156, out./dez. 2012.

ROBERTSON, S. As implicações em justiça social da privatização nos modelos de governança da educação: um relato relacional. Educação e Sociedade, Campinas, v. 34, n. 124, p. 679-703, jul./set. 2013.

RODRIGUEZ, M. V. et al. Formação e avaliação de diretores de escolas no âmbito da parceria entre municípios e o Instituto Ayrton Senna. Educere et Educare, Cascavel, PR, v. 5, n. 10, p. 163-179, jul./dez. 2010.

SHIROMA, E. O.; GARCIA, R. M. C.; CAMPOS, R. F. Conversão das “almas” pela liturgia da palavra: uma análise do discurso do movimento Todos pela Educação. In: BALL, S. J.; MAINARDES, J. (Orgs.). Políticas educacionais: questões e dilemas. São Paulo: Cortez, 2011. p. 222-247.

SOUZA, S. Z. L. de; OLIVEIRA, R. P. de. Políticas de avaliação da educação e quase mercado no Brasil. Educação \& Sociedade, Campinas, vol. 24, n. 84, p. 873-896, 2003.

VERGER, A.; BONAL, X. La estrategia educativa 2020 o las limitaciones del Banco Mundial para promover el "aprendizaje para todos". Educação \& Sociedade, Campinas, v. 32, n. 117, p. 911-932, out./dez. 2011.

Artigo recebido em: 30/12/2015

Artigo aceito em: 18/07/2016 